\title{
Test-and-treat approach to ending HIV epidemic in Nigeria: current status and future prospects of domestic funding
}

\author{
Babayemi O. Olakunde ${ }^{1}$, Daniel A. Adeyinka ${ }^{2,3}$ \\ ${ }^{1}$ National Agency for the Control of AIDS, Abuja, Nigeria \\ ${ }^{2}$ National AIDS \& STIs Control Programme, Federal Ministry of Health, Abuja, Nigeria \\ ${ }^{3}$ University of Saskatchewan, Saskatoon, Canada
}

\begin{abstract}
The World Health Organization (WHO) new recommendation of initiation antiretroviral therapy to every human immunodeficiency virus (HIV)-infected person regardless of the CD4 cell count or WHO clinical stage will enhance the global goal of ending the HIV epidemic. The adoption and implementation of this test-and-treat approach is imperative in high burden countries in sub-Saharan Africa, where HIV remains a huge threat to human and economic development. However, this approach requires a front-loading investment as the number of people requiring care and treatment will increase considerably. While domestic funding in the global HIV response has significantly improved over the years, a number of countries in sub-Saharan Africa are still reliant on donor support. With international funding of HIV flattening out, it is critical that donor dependent countries for HIV services begin to explore innovative and sustainable means to generate funds and complement international donors' efforts in increasing access to HIV care and treatment. For a high burden country like Nigeria, where international support accounts for over $70 \%$ of the HIV expenditure, improving domestic funding is certainly imperative for the implementation of test-and-treat approach. This paper highlights the current status and the untapped potentials for improved domestic funding and access to antiretroviral therapy in Nigeria.
\end{abstract}

HIV AIDS Rev 2017; 16, 4: 205-211

DOI: https://doi.org/10.5114/hivar.2017.72013

Key words: domestic funding, HIV, test-and-treat, Nigeria.

\section{Introduction}

In the 2016, in consolidated guidelines on the use of antiretroviral drugs for treating and preventing human immunodeficiency virus (HIV) infection, the World Health Organization (WHO) recommends that antiretroviral therapy (ART) should be initiated in every HIV-infected person regardless of their WHO clinical stage and CD4 cell count [1]. This testand-treat approach is a departure from previous recommendations of certain thresholds to determine eligibility for ART.
The recommendation, which is in keeping with the global goal to ending HIV epidemic as a major public threat by bringing treatment to all [2], is expected to shape national HIV treatment guidelines particularly in countries with high HIV burden. However, countries that adopt this policy will have to increase their financial commitment to their HIV response [3]. It will require an initial front-loading investment for long-term gains [4].

With about 3.2 million people living with HIV (PLHIV) as at 2016, Nigeria has the second highest burden of HIV 
globally [5]. This huge burden continues to impact on its human and economic development. The Nigerian ART program commenced in 2002, and it has evolved over the years, particularly in line with WHO recommendations. In 2015, it was estimated that about 2.3 million PLHIV were eligible for ART, however only about $38 \%$ received ART [5]. With the adoption of the 2016 WHO recommendations - which makes all the PLHIV now eligible for ART - the number of PLHIV receiving ART increased from 809,304 in 2015 to 927,769 in 2016.

While the importance of test-and-treat approach in ending the HIV epidemic is not in doubt, financing this approach is of great concern in the light of the economic downturn and the dwindling donor fund for HIV [6]. For a high burden country like Nigeria, where international support accounts for over 70\% of the HIV expenditure [7], improving domestic funding to complement the international funds is certainly imperative. Innovative financing means can contribute to domestic funding in sub-Saharan Africa [8]; however, many countries have not been exploring the available financing opportunities [9].

In this paper, we highlight the current status and the untapped potentials for improved domestic funding and access to antiretroviral therapy in Nigeria.

\section{Current status of domestic funding}

\section{Public fund}

Domestic funding from government coffers is a significant component of the global HIV funding. It has significantly improved over the years, overtaking international funds in the global HIV response. In 2016, domestic funding accounted for about $57 \%$ of the total resources available for HIV/AIDS in low- and middle-income countries [10]. Despite the progress, a number of countries are still reliant on donor support [11].

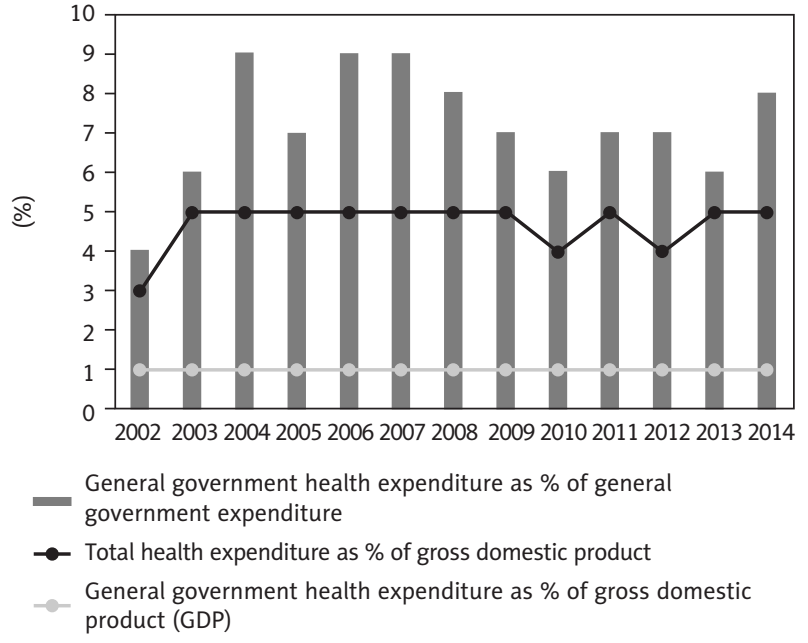

Figure 1. General government health expenditure in Nigeria Source: World Health Organization Global Health Expenditure Database

Government expenditure on health in Nigeria has been below par over the years. Since the Abuja Declaration in 2001, the Nigerian government is yet to meet the allocation of $15 \%$ of its annual budget to health. The general government expenditure on health as a percentage of the total general government expenditure from 2002-2014 ranged from $4 \%$ to $9 \%$ [12] (Fig. 1). The general government expenditure on health has not increased commensurably with the growing gross domestic product.

From 2007 to 2014, the public expenditure on HIV ranged between US\$ $30,082,450$ and US\$ $171,174,761$, accounting for $8-27 \%$ of the total HIV expenditure (Fig. 2) [7]. The expenditure has perpetually fallen short of the commitment to $50 \%$ domestic funding in the 2010 partnership framework with the US President's Emergency Plan for AIDS Relief (PEPFAR) [13]. The National AIDS Spending

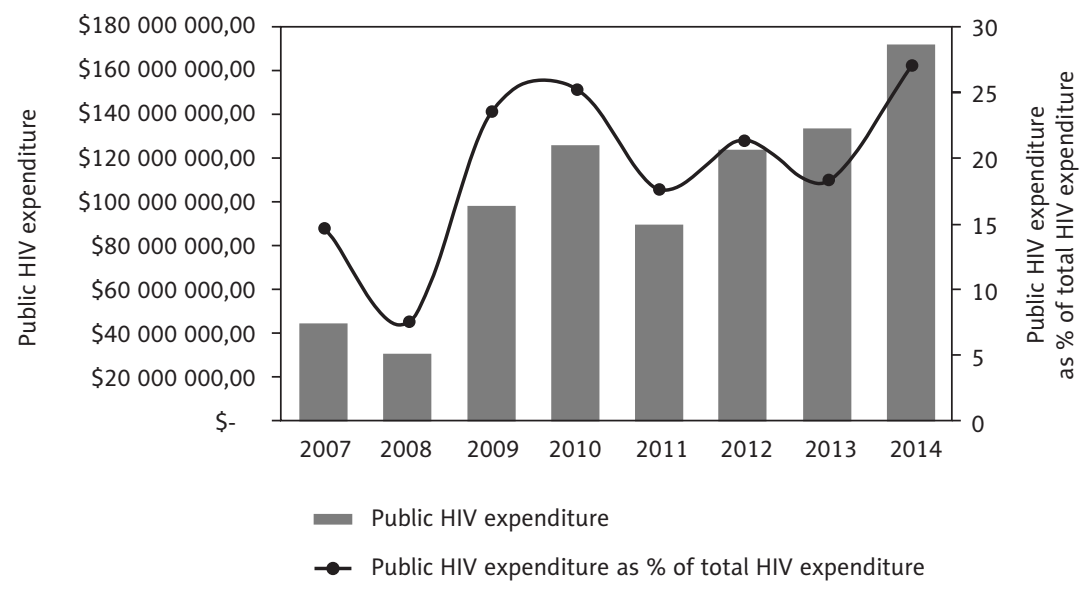

Figure 2. Trend in public expenditure on HIV in Nigeria

Sources: NASA 2007-2008, 2009-2010, 2011-2012, and 2013-2014 


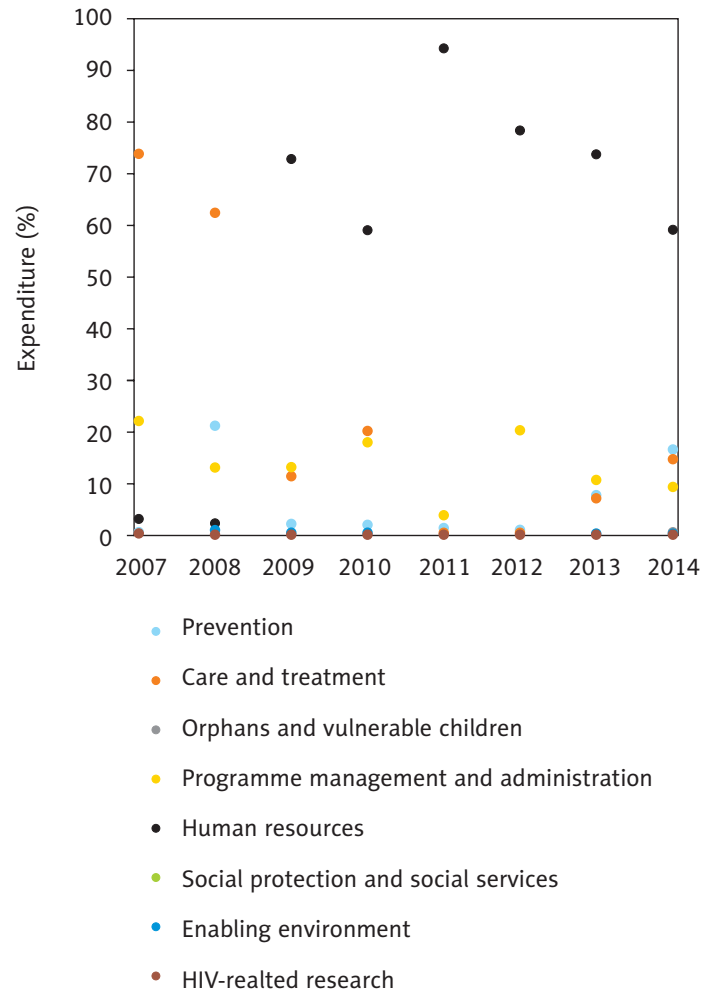

Figure 3. Spending pattern of public funds on HIV in Nigeria Sources: NASA 2007-2008, 2009-2010, 2011-2012, and 2013-2014

Assessment (NASA) reports show that a preponderant portion of the public fund is expenditure on human resources (Fig. 3). For example in 2014, 59\% of the expenditure was on human resources, while prevention was $16 \%$, and care and treatment was $15 \%$ [7].

However, the federal government took steps to improve domestic investment in comprehensive HIV program. In 2014, savings from partial removal of oil subsidy through the Subsidy Re-investment and Empowerment Program (SURE-P) was used to commence HIV program in two states transitioned by PEPFAR to the government of Nigeria [14]. The funding source for the program recently changed to budgetary allocation after termination of SURE-P.

\section{Private funding}

Private organizations play a key role in global funding of HIV. They include foundations, corporations, faith-based organizations, non-government organizations as well as individuals that philanthropically support HIV programs [15]. However, the influx of donor funding has crowded-out private sector investment and contribution to HIV [16]. The private sector is also important in service delivery, including pharmaceuticals for HIV [17].

The organized private sector in Nigeria has made little and unpredictable investment in the HIV response. From 2008 to 2014, the private sector's contribution to the total HIV expenditure ranged between $0.1-2.0 \%$ with a significant portion of resources expended on prevention activities and program management (Figs. 4 and 5). In 2014, prevention accounted for $82 \%$ of the expenditure, while care and treatment was only $9 \%$ [7]. There is also limited involvement of the private health sector in ART service provision despite being a major player in healthcare service delivery in Nigeria [18].

\section{Untapped funding potentials}

The Nigerian government revenue is largely oil dependent, and the vagaries of oil prices will continue to affect the fiscal space, and consequently, the budgetary allocation to health and HIV [19]. The diversification of the monoproduct economy to improve government's revenue is very critical. In addition to direct budgetary allocations, other

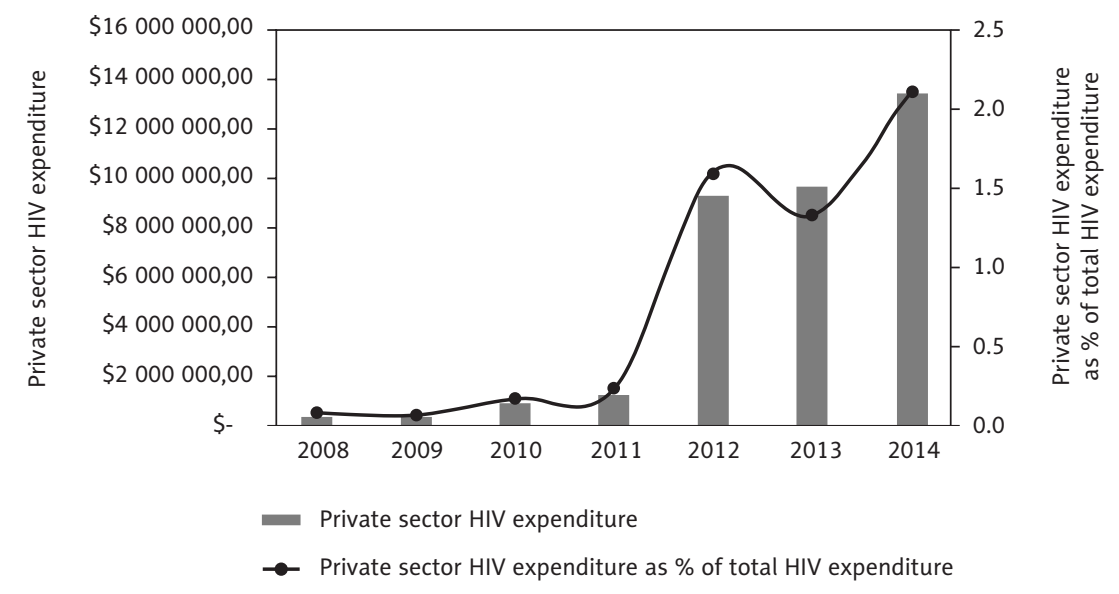

Figure 4. Trend in private sector expenditure on HIV in Nigeria Sources: NASA 2007-2008, 2009-2010, 2011-2012, and 2013-2014 


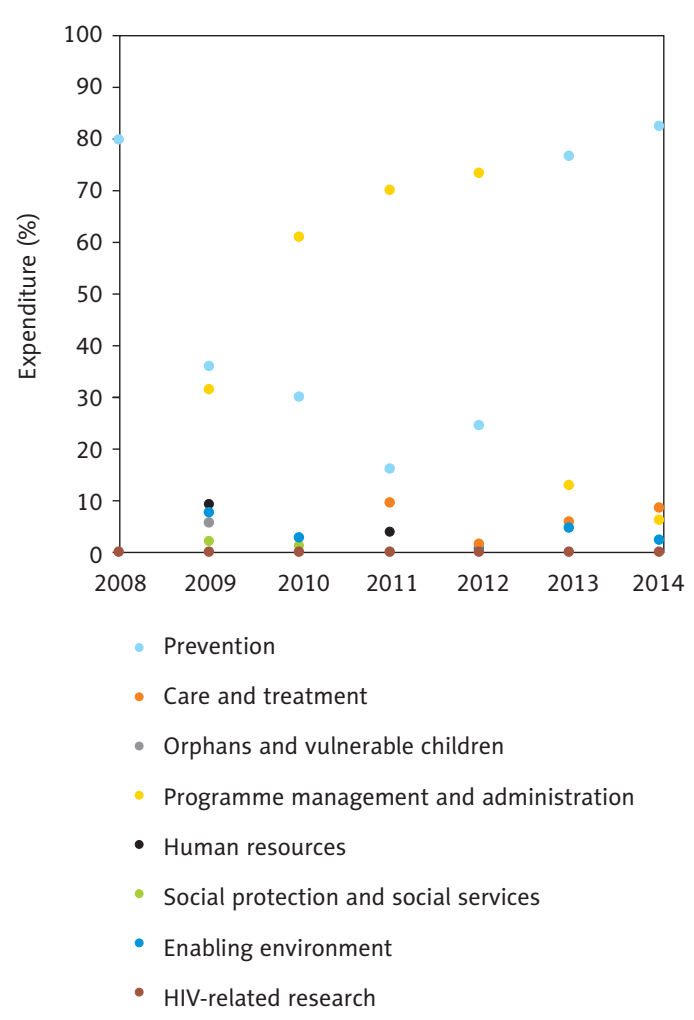

Figure 5. Spending pattern of private funds on HIV in Nigeria Sources: NASA 2007-2008, 2009-2010, 2011-2012, and 2013-2014

sustainable means to domestically fund and increase access to HIV need to be considered.

\section{Earmarking}

Earmarking taxes for HIV is a sustainable approach that has been implemented in low- and middle-income countries [20]. Taxes or levies are commonly introduced in sectors like telecommunications and aviation, or on alcohol and tobacco. AIDS levy on taxable income of institutions and individuals in formal sector for HIV response are also operational in a number of developing countries [20]. In Zimbabwe, AIDS levy is estimated to generate about US \$ 35 million annually for the national HIV response [21].

Introduction of taxes or levies in similar sectors in Nigeria can generate considerable revenue that can be earmarked for the HIV response. For example, in the aviation sector, the average annual total passenger traffic on both domestic and international flights is about 14 million [22]. International airlines that operated international destinations from Nigeria made an estimated US \$ 15 billion in 2015 [23].

While earmarking for funding HIV response has garnered interest, it has been argued that introduction of taxes can reduce the demand or the consumption for the items, which will eventually result in lowered revenue [24]. But a small surtax may not necessarily have such an impact, particularly for items that have low price elasticity [25]. Others have pointed to budgetary inflexibility and discouragement from the use of broader tax revenues to fund the HIV response [26-28]. However, given that the revenue generated from the earmarked taxes may not be sufficient for the entire response, it is more likely to be seen as complementary. Nevertheless, in designing this funding mechanism, it is important to carefully consider what to tax, existing tax burden, ease of implementation, and the potential effects.

\section{Trust fund}

Specific trust fund for HIV has been set-up in some developing countries to support HIV funding [20]. This can also be replicated in Nigeria. In 2013, the President's Comprehensive Response Plan proposed a matching grant model with the federal government and state governments providing resources to the pool in an equal ratio [20]. If revisited, this funding arrangement could operate as HIV trust fund for care and treatment of PLHIV.

In the recently promulgated Health Act, the government created a special Basic Health Care Provision Fund with a commitment of not less than $1 \%$ of its consolidated revenue fund to the special fund in addition to funds from grants by international donor partners and other sources [29]. The fund is to be used for provision of minimum package of health services to the citizens through the National Health Insurance Scheme (NHIS), and also to strengthen the primary healthcare system. A proportion of this fund could also be used to support provision of HIV services.

\section{Private sector involvement}

The impact of HIV on businesses should stimulate private sector involvement in the response [30]. Although a business coalition against HIV exist in Nigeria, its activities have been limited to supporting businesses to establish and implement HIV workplace and community-based prevention programs [31]. The coalition can initiate the establishment of HIV corporate sector fund, which will accept contributions from local and international private sector companies. An example is the Indo-US Corporate Fund for HIV, which receives donations from Indian and US businesses to expand and strengthen India's response to HIV [32].

The organized private sector can be involved in HIV response as part of their Corporate Social Responsibility (CSR). In some countries, there are legislations mandating businesses to contribute a certain percentage of their profit to CSR including health and HIV $[33,34]$. Although mandatory CSR practices remains moot [35], without compulsion, only a few organizations participate in CSR voluntarily. Private organizations set-up as social enterprises are also required for the response [36].

There is a good case for engaging the private health sector for scaling up ART coverage in developing countries where the account for over $50 \%$ of service delivery $[37,38]$. However, there are concerns about their performance in 
a poorly regulated system $[37,39,40]$. To involve more private health sector in HIV service in Nigeria, it is crucial to identify model(s) for effective engagement [41]. This will also include putting in place systems that will enhance their performance. This can be achieved through market based approach (contracting, financing, franchising, social marketing, and collaborating), administrative approach (regulating and training), and public empowerment approach (informing and educating) [42].

\section{Local manufacturing of ARVs}

With the provisions and flexibility in the Trade-Related Aspects of Intellectual Property Rights agreement and Doha declaration of 2001, which allow developing countries to produce and purchase generic patented medicines during public health crises [43], there has been growing interest in local production of ARVs to improve access to ART. This is however premised on the condition that ARVs that meet WHO prequalification can be produced more cheaply locally [44]. Despite the complexities, manufacturing of WHO prequalified ARV locally has successfully taken off in some African countries like Kenya, South Africa, Uganda, and Zimbabwe [45]. Nigeria has also been considered for the possibility of producing ARVs locally [46].

Nigeria has the potential to be the center for manufacturing of essential drugs in sub-Saharan Africa, but its capacity is underutilized [47]. Government can promote and support local production of ARVs by encouraging and provide enabling environment for the private sector [48].

\section{Health insurance}

PLHIV in Nigeria incur significant out-of-pocket expenditure (OOP) on HIV related services such as ARVs, laboratory tests, and consumables [49]. Even where these services are meant to be free, expenditure from unauthorized fees are not uncommon. It is estimated that $14.5 \%$ proportion of household income is used for HIV-related services in Nigeria [49]. This catastrophic expenditure on HIV can impact negatively on access to care. With PEPFAR's withdrawal from provision of certain laboratory services [14], OOP expenditure for PLHIV is expected to increase.

Financial protection for PLHIV is important in ensuring access to treatment by all. While the chronic nature of HIV might present challenges for its inclusion in health insurance schemes [24], insurance schemes for HIV-related services have been introduced in some countries, with various types of insurance models (national, social, private, and community schemes) being used to reach different strata within the society [50].

HIV treatment is currently not covered for any of the prepayment programs in the Nigeria NHIS [51]. For private insurance companies, the perception that schemes for HIV treatment is expensive and unsustainable has limited its coverage [52]. Community insurance scheme operated through a public-private partnership has only been used to provide coverage for opportunistic infections [53].

To expand insurance coverage for HIV-related services including ART in Nigeria, the potential of the existing models to generate sufficient pool, ensure equity, reduce adverse selection, and moral hazard need to be carefully considered. For instance, the NHIS still has a very poor pool as a result of low participation at the sub-national level and uptake by the non-formal sector. There is a need for government to expedite expansion and ensure a strong regulatory environment.

\section{Efficient use of resources}

Efficient use of the available domestic fund for maximum impact is imperative. The scarce resources should be allocated in a way that it will give a good return on investment. Task shifting in the delivery of ART can lower the cost of managing HIV programs and increase access to care and treatment [54]. There is a need for reduction in the huge expenditure on program management and human resources, which account for about third of total expenditure from all sources. The use of government structures in place of the non-governmental organizations might be more cost saving approach to implement HIV/AIDS program [14].

A robust coordinating mechanism of the response at all levels is essential, such that all the resources available from different sources are aligned, harmonized, and used efficiently to pursue a common goal.

\section{Conclusions}

There are untapped sustainable funding opportunities for Nigeria to invest in test-and-treat approach and bring treatment to all PLHIV. With strong political will and enabling policies, the government in tandem with the private sector can generate funds domestically to complement international donors support in increasing access to ART. A robust national HIV sustainable financing plan that considers these promising and other innovative means of generating funds are recommended.

\section{Conflict of interest}

The authors declare no potential conflicts of interest with respect to the research, authorship, and/or publication of this article.

\section{References}

1. World Health Organization (WHO). Consolidated guidelines on the use of antiretroviral drugs for treating and preventing HIV infection: recommendations for a public health approach $2^{\text {nd }}$ ed. WHO, Geneva 2016.

2. Joint United Nations Programme on HIV/AIDS (UNAIDS). 90-90-90: an ambitious treatment target to help end the AIDS epidemic. UNAIDS, Geneva 2014.

3. Dutta A, Barker C, Kallarakal A. The HIV Treatment Gap: Estimates of the Financial Resources Needed versus Available for 
Scale-Up of Antiretroviral Therapy in 97 Countries from 2015 to 2020 . PLoS Med 2015; 12: e1001907.

4. Joint United Nations Programme on HIV/AIDS (UNAIDS). Fasttrack update on investments needed in the AIDS response. UNAIDS, Geneva 2016.

5. National Agency for the Control of AIDS (NACA). National HIV/ AIDS Epidemiology and Impact Analysis (NHEIA) Report. NACA, Abuja 2017.

6. Kates J, Wexler A, Lief E. Joint United Nations Programme on HIV/AIDS, Donor governments funding for HIV in low-and middle-income countries in 2016. The Henry J Kaiser Family Foundation, Menlo Park 2017.

7. National Agency for the Control of AIDS (NACA). National AIDS Spending Assessment Report 2013-2014. NACA, Abuja 2015.

8. Atun R, Silva S, Ncube M, Vassall A. Innovative financing for HIV response in sub-Saharan Africa. J Glob Health 2016; 6: 010407.

9. Remme M, Siapka M, Sterck O, et al. Financing the HIV response in sub-Saharan Africa from domestic sources: Moving beyond a normative approach. Soc Sci Med 2016; 169: 66-76.

10. Joint United Nations Programme on HIV/AIDS (UNAIDS), Fact Sheet: 2016 Global Statistics. Available at: http://www.unaids.org/ sites/default/files/media_asset/UNAIDS_FactSheet_en.pdf (Accessed: 10.10.2017).

11. Resch S, Ryckman T, Hecht R. Funding AIDS programmes in the era of shared responsibility: an analysis of domestic spending in 12 low-income and middle-income countries. Lancet Glob Health 2015; 3: e52-e61.

12. World Health Organization (WHO), Global Health Expenditure Database. Available at: http://apps.who.int/nha/database (Accessed: 11.05.2016).

13. US President's Emergency Plan for AIDS Relief, Partnering to Achieve Epidemic Control in Nigeria. Available at: http://www. pepfar.gov/countries/nigeria/ (Accessed: 14.05.2016).

14. Olakunde BO, Ndukwe CD. Improved domestic funding enhances sustainability of HIV/AIDS response in Nigeria. Ann Glob Health 2015; 81: 684-688.

15. Kates J, Wexler A, Lief E. Financing the response to HIV in lowand middle-income countries: international assistance from donor governments in 2014. The Henry J Kaiser Family Foundation, Menlo Park 2015.

16. Sulzbach S, De S, Wang W. The private sector role in HIV/AIDS in the context of an expanded global response: expenditure trends in five sub-Saharan African countries. Health Policy Plan 2011; 26: i72-i84.

17. Arur A, Sulzbach S, Barnes J, et al. Strengthening the Health Sector by Engaging the Private Sector: Promising HIV/AIDS Partnerships, SHOPS Project. Abt Associates, Bethesda 2010.

18. National Agency for the Control of AIDS (NACA). Global AIDS Response Country Progress Report, NACA, Abuja 2015.

19. Olakunde BO. Public health care financing in Nigeria: which way forward? Ann Niger Med 2012; 6: 4-10.

20. Joint United Nations Programme on HIV/AIDS (UNAIDS). Efficient and Sustainable HIV Responses: Case studies on country progress. UNAIDS, Geneva 2013.

21. Bhat N, Kilmarx PF, Dube F, et al. Zimbabwe's national AIDS levy: A case study. J Soc Asp HIV/AIDS 2016; 13: 1-7.

22. Nigeria Bureau of Statistics, Nigerian Aviation Sector: Summary Report: Q4 and Full Year 2015. Available at: http://www.nigerianstat.gov.ng/report/391 (Accessed: 20.05.2016).

23. Eze C. International Airlines Operators in Nigeria Earn N302bn from Ticket Sales, Thursday Newspaper $29^{\text {th }}$ April 2016. Available at: http://www.thisdaylive.com/index.php/2016/04/29/international-airlines-operators-in-nigeria-earn-n302bn-from-ticket-sales/ (Accessed: 20.05.2016).

24. Katz I, Routh S, Bitran R, et al. Where will the money come from? Alternative mechanisms to HIV donor funding. BMC Public Health 2014; 14: 956.
25. Nghiem N, Wilson N, Genc M, Blakely T. Understanding Price Elasticities to inform Public Health Research and Intervention Studies: Key Issues. Am J Public Health 2013; 103: 1954-1961.

26. Vassall A, Remme M, Watts C, et al. Financing Essential HIV Services: A New Economic Agenda. PLoS Med 2013; 10: e1001567.

27. Prakongsai P, Patcharanarumol W, Tangcharoensathien V. Can earmarking mobilize and sustain resources to the health sector? Bull World Health Organ 2008; 86: 898-901.

28. National Agency for the Control of AIDS (NACA). President's Comprehensive Response Plan 2014-2015 (PCRP). NACA, Abuja 2015.

29. National Health Act 2014, Available at: http://www.nphcda.gov.ng/ Reports\%20and\%20Publications/Official\%20Gazette\%20of\%20 the\%20National\%20Health\%20Act.pdf (Accessed: 20.05.2016).

30. Rosen S, Vincent JR, Macleod W, et al. The cost of HIV/AIDS to businesses in southern Africa. AIDS 2004; 18: 317-324.

31. Nigerian Business Coalition Against AIDS (NIBUCAA). Available at: http://nibucaa.org/nibucaa/ (Accessed: 20.05.2016).

32. Indo-US Corporate Fund for HIV/AIDS. Available at: file:///C:/ Users/YEMI-PC/Downloads/2901_file_New_final_USAID_mailer\%20(2).pdf (Accessed: 20.05.2016).

33. Waagstein PR. The mandatory corporate social responsibility in Indonesia: Problems and Implications. J Bus Ethics 2011; 98: 455-466.

34. Singh A, Verma P. From Philanthropy to Mandatory CSR: A Journey towards Mandatory Corporate Social Responsibility in India. Int J Bus Manag Invent 2014; 6: 146-152.

35. Japhet K, Tawiah VK, Benjamin M. Debate on Mandatory Corporate Social Responsibility. Presented in: National Seminar on Strategies for Business Excellence in Global Era in Haryana State, India, 2015. Available at: file:///C:/Users/YEMI-PC/Downloads/ SSRN-id2592880\%20(1).pdf (Accessed: 20.05.2016).

36. Roy MJ, Donaldson C, Baker R, Kay A. Social enterprise: New pathways to health and well-being? J Public Health Policy 2013; 34: 55-68.

37. Rao P, Gabre-Kidan T, Mubangizi DB, Sulzbach S. Leveraging the Private Health Sector to Enhance HIV service Delivery in LowerIncome Countries. J Acquir Immune Defic Syndr 2011; 57: 116-119.

38. Wang W, Sulzbach S, De S. Utilization of HIV-Related Services from the Private Health Sector: A Multi-Country Analysis. ICF Macro, Calverton 2010.

39. Ezechi OC, Oladele DA, Dureke F, et al. Private Sector Engagement in the National HIV Response in Nigeria: Findings from a Nationally Representative Sample of Stakeholders. Niger J Health Sci 2014; 14: 23-28.

40. Osungbade KO, Shaahu VN, Owoaje EE, Adedokun BO. Patients' Satisfaction with Quality of Anti-Retroviral Services in Central Nigeria: Implications for Strengthening Private Health Services. World J Prev Med 2013; 1: 11-18.

41. John S, Johnson J, Majorowski M, et al. Private Sector Involvement in HIV Service Provision, USAID AIDSTAR-One Project. Task Order 1, Arlington 2009.

42. Peters DH, Mirchandani GG, Hansen PM. Strategies for engaging the private sector in sexual and reproductive health: how effective are they? Health Policy Plan 2004; 19 (Suppl 1): i5-i21.

43. Joint United Nations Programmes on HIV/AIDS (UNAIDS), DOHA+10 Trips Flexibilities and Access to Antiretroviral Therapy: Lessons from the Past, Opportunities for the Future. UNAIDS, Geneva 2011.

44. Wilson K, Cohen-Kohler J, Whiteside A. The Price is Right? Promoting local production for ARVs in Sub-Saharan Africa. Eurohealth 2008; 14: 29-32.

45. Joint United Nations Programme on HIV/AIDS (UNAIDS). Shared responsibility and global solidarity. Leveraging the AIDS response for Africa's sustainable development: Africa in the lead. Available at: http://www.unaids.org/sites/default/files/en/media/unaids/contentassets/documents/document/2012/20120926_shared_responsibility_en.pdf (Accessed: 23.05.2016). 
46. UNAIDS plans antiretroviral manufacturing plant in Nigeria. Available at: http://www.punchng.com/31716-2/ (Accessed: 27.05.2016).

47. United Nations Industrial Development Organization (UNIDO). Pharmaceutical Sector Profile: Nigeria. UNIDO, Vienna 2011.

48. Pinheiro ED, Bruning K, Macedo MF, Siani AC. Production of antiretroviral drugs in middle-and low-income countries. Antiviral Ther 2014; 19(S3): 49-55.

49. Adeoye IY, Ogungbemi K, Adaoha A, Adedayo A. Out-of-pocket expenditure on HIV/AIDS: best practice from Nigeria. In: $19^{\text {th }}$ International AIDS conference in Washington DC, USA, 2012. Available at: http://pag.aids2012.org/Abstracts.aspx?AID=8706 (Accessed: 23.05.2016)

50. Switlick-Prose K, Loomis M. Risky Business? Financial Protection for People Living With HIV/AIDS A Review of International Experiences, Health Systems 20/20 Project. Abt Associates Inc., Bethesda 2010.

51. Nigerian Health Insurance Scheme. Available at: http://www.nhis. gov.ng/ (Accessed: 26.05.2016).

52. Talib A, Hatt L. Expanding private health insurance coverage for HIV and AIDS in Sub-Saharan Africa The Strengthening Health Outcomes through the Private Sector (SHOPS). Abt Associates Inc., Bethesda 2013.

53. Pharmaccess Foundation, Health Insurance Programs. Available at: http://www.pharmaccess.org/RunScript.asp?Page=412\&p=ASP Pg412.asp (Accessed: 26.05.2016).

54. Mdege ND, Chindove S, Ali S. The effectiveness and cost implications of task-shifting in the delivery of antiretroviral therapy to HIV-infected patients: a systematic review. Health Policy Plan 2012; 28: 223-236. 